Int. J. Electrochem. Sci., 12 (2017) $6081-6091$

\title{
Effect of Graphene on Micro-Structure and Properties of MAO Coating Prepared on Mg-Li Alloy
}

\author{
Fei Chen", Yulin Zhang and You Zhang \\ Beijing Key Lab of Special Elastomeric Composite Materials, College of Materials Science and \\ Engineering, Beijing Institute of Petrochemical Technology, Beijing 102617, China \\ *E-mail: chenfei_bipt@126.com
}

doi: $10.20964 / 2017.07 .59$

Received: 24 March 2017 / Accepted: 29 April 2017 / Published: 12 June 2017

Ceramic coating modified with graphene was formed on $\mathrm{Mg}-\mathrm{Li}$ alloy by a micro-arc oxidation process in a graphene powders (GE) added silicate electrolyte. The microstructure, composition, tribological and corrosion behaviors of the coatings were performed. The results showed that the added GE promote the formation of hard $\mathrm{MgO}$ and $\mathrm{SiO}_{2}$ phases in $\mathrm{MAO}$ film and result in low friction coefficient and enhanced wear resistance. C element was also detected on the surface of the GE added film. With the addition of GE in silicate electrolyte, the corrosion resistance of the composite coating was improved significantly owing to the pore size decreases and film thickness increases.

Keywords: Micro-arc oxidation; Graphene; Wear resistance; Corrosion resistance

\section{FULL TEXT}

(C) 2017 The Authors. Published by ESG (www.electrochemsci.org). This article is an open access article distributed under the terms and conditions of the Creative Commons Attribution license (http://creativecommons.org/licenses/by/4.0/). 